\title{
Computer animation data management: Review of evolution phases and emerging issues
}

\author{
Hui Liang ${ }^{1}$, Jason Sit ${ }^{1}$, Jian Chang ${ }^{1}$, Jian Jun Zhang ${ }^{1}$ \\ ${ }^{1}$ Centre for computer animation, Bournemouth University, Poole, BH12 5BB, UK \\ "liangh@bournemouth.ac.uk
}

\begin{abstract}
The computer animation industry has been booming and prospering in recent thirty years. One of the significant changes faced by this industry is the evolution of computer-animation data and, yet, extant literature has offered very little insights into the evolution process and management issues pertinent to computer-animation data. Hence, many questions have surfaced in the extant literature of computeranimation data management. For example, to what extent has the data content expanded in terms of quantity and quality? To what extent has the information technology used to store and process the data changed? To what extent have the user and the community groups diversified in terms of their nature and number? Knowledge pertaining to these issues can provide new research directions to academics and also insights to practitioners for more effective and innovative management of computer-animation data. This conceptual paper, therefore, takes the pioneering step to address these issues by proposing four factors prudent for examining the evolution phases associated with computer-animation data management: technology, content, users, and community. Next, this paper presents a conceptual framework illustrating the inter-dependent relationships between these four factors together with associated theoretical and managerial issues. This paper, albeit limited by its conceptual nature, advances the extant literature of computer animation, information system, and open-product model.
\end{abstract}

Keywords: Computer animation, Data management, Evolution, Emerging issues, Review, Open product model, Framework

\section{Introduction}

Through a long history of development (Thalmann et al, 1996; Collins, 1997), computer animation has become a prospering industry characterised by high growth: the total market revenue of the 
computer animation industry was reported to be around USD122.20 billion in 2010 and is forecasted to reach USD242.93 billion in 2016. The compound annual growth rate (CAGR) of the global animation industry is estimated to have risen by $12.94 \%$ in recent years (Deloitte, 2010; Markets and Markets, 2011).

Given the rapid growth of the computer animation industry, practitioners are faced with many challenges and amongst them include the constant and speedy generation of data, in mammoth volume, and from varied sources. For example, Lune et le Loup (2014), a French short animation film in 2014, it's running time is only 6.26 minutes while the animation data of all the frames reached up to 1.5 TB. Some individual frames of the movie Interstellar (2015) took up to 100 hours to render, and resulted in 800 terabytes of data to create the satisfactory visual effects. Varied parties were involved in co-producing, co-using, and co-sharing the huge volume of animation data, including visual effects supervisor, a team of 30 people at the visual effects company, a theoretical physicist that served as scientific consultant, and executive producer/s. Consequently, in future film animation will rely more heavily on technology for data processing and management. Both the current and future modus operandi of animation data management urgently call for re-thinking and re-designing in order to address the escalating amount of the animation data more effectively.

There is a disconnection between business practices and academic research in relation to computeranimation data management, especially in relation to its evolution phases. Extant literature of information system offers little insights into the evolution of computer animation system related to issues such as, for example, the extent to which information system used to manage animation data has changed, the extent to which the animation data content has expanded, and the nature of the user and community groups has diversified. The purpose of this paper is twofold, that is, to:

1). address the disconnection between business practices and academic research in relation to computer-animation data management. More specifically, it reviews relevant literature to identify the evolution phases relating to computer-animation data management;

2). propose a list of emerging issues, together with research and managerial insights, relating to computer-animation data management. 
The rest of this paper is structured in three parts: the next section reviews the animation data evolution based on different phases. Emerging issues pertaining to the computer-animation industry are presented in the following section. Finally, an open production model is presented to illustrate the animation data evolution.

\section{Literature review}

To critically examine and insightfully explain how animation data management processes and practices have evolved over the three decades, the literature review of this conceptual paper drew upon the systematic procedure used by Soomro et al. (2016), which comprises three key stages: searching the literature; selecting the literature; and analysing the identified literature.

\subsection{Searching the literature}

In this stage, Soomro et al. (2016) emphasized the issues of reliability and validity, whereby reliability is derived from meaningful keywords used for the literature search, selected databases, publications, and the covered period, and validity is derived from meaningful articles included and reviewed for addressing the research objectives. Drawn on these suggestions, the literature search of this paper began with the identification of the key words relevant for addressing the research questions via discussions between the researchers. Five key words were identified, namely, data management, animation production, animation data, animation industry. The discussions also yielded four databases and one search engine pertinent for the literature search: ACM Digital Library; IEEE Explore; EBSCO; Science Direct; and Google Scholar. The literature search covered the period of thirty years, whereby computer animation gained popularity or attention in the mass media after 1990s. The keyword search involved using several terminologies: "data management" OR "animation data" OR "animation production" (independently and collectively); "data management" AND "animation industry" OR "animation production"; "media data" AND "animation industry" OR "animation production". To obtain additional eligible articles, the reference lists of the filtered articles were also checked.

\subsection{Selecting the literature}


After downloading, the list was checked for repetitions and duplicate articles were removed from the list. Next, the abstract of each article (or the introduction of a book chapter or a report) was perused and further filtering took place. Selection of meaningful articles was based on agreed inclusion and exclusion criteria. More specifically, full-text articles published in international academic peerreviewed journals or in international scientific conferences were included. Book chapters by reputable authors, and trade reports (e.g. market and company reports) by credible sources were also included. However, conference proceedings with abstracts only and dissertations were excluded. Moreover, included articles must have either conceptually discussed or empirically examined the topics of data management and/or media data within the computer animation context. Studies examined data management, or those that focused on media data, but did not specifically relate to computer animation were excluded. Only articles published in the English language were included. To determine articles' relevance to the context under study, abstracts were perused (for book chapters or trade reports, the introduction was read). Consequently, a total of 85 articles were deemed meaningful for the literature review of this paper (see Table 1).

Table 1 - List of data bases and search engine used for literature search

\begin{tabular}{l|l|l}
\hline S. No & Name of database/ search engine & Number of articles \\
\hline 1 & ACM Digital Library & 7 \\
2 & IEEE Explore & 24 \\
3 & EBSCO & 11 \\
4 & Science Direct & 15 \\
5 & Google Scholar & 28 \\
\hline
\end{tabular}

\subsection{Analyzing the identified literature}

Three researchers independently reviewed the 85 included articles, and then compared and contrasted their findings. Divergent views on findings were resolved via discussions, and their findings were grouped into three convergent themes: evolution phases of computer-animation data management; 
emerging issues; and open-production model involving multiple stakeholders. Each of these convergent themes is discussed in detail next.

\section{Evolution phases of computer-animation data management}

Different from the conventional hand-drawn animation, computer animation uses computer graphics to generate animated images. Benefited from the development of computer science, encompassing a variety of techniques, such as keyframe animation and inbetween (Lasseter, 1987), and currently commonly used motion capture and simulation (Parent, 2012), animation could be produced in a costeffective manner with higher quality. Computer technology has revolutionised the production of animation. Before the $1980 \mathrm{~s}$, animation production typically took the form of traditional handdrawing production mode. After 1980s, the computer animation production accelerated, and was attributed to the computer hardware development. Since then, data has become an essential part of computer animation, and has evolved to be more complex and mammoth in nature and this phenomenon is coined as the birth of "Big Data" (Manyika et al., 2011; Shacklett, 2014). The word "big data" stated in this paper mainly refers to the massive volume of animation data rather than the broad term for large/complex data sets/data analysis used in current information world to provide enhanced insight and decision making in general meaning.

The literature review alludes that the evolution of computer animation data consists of four phases: phase 1 (the 1980s), phase 2 (1990 2005), phase 3 (2006 present) and the "big data" phase (next generation) as illustrated in Fig. 1. Each of these evolution phases is characterised by four dimensions: Technology, Content, User and Community, which finally lead to an Open Production Model for computer animation depicted in Section 5.1. 


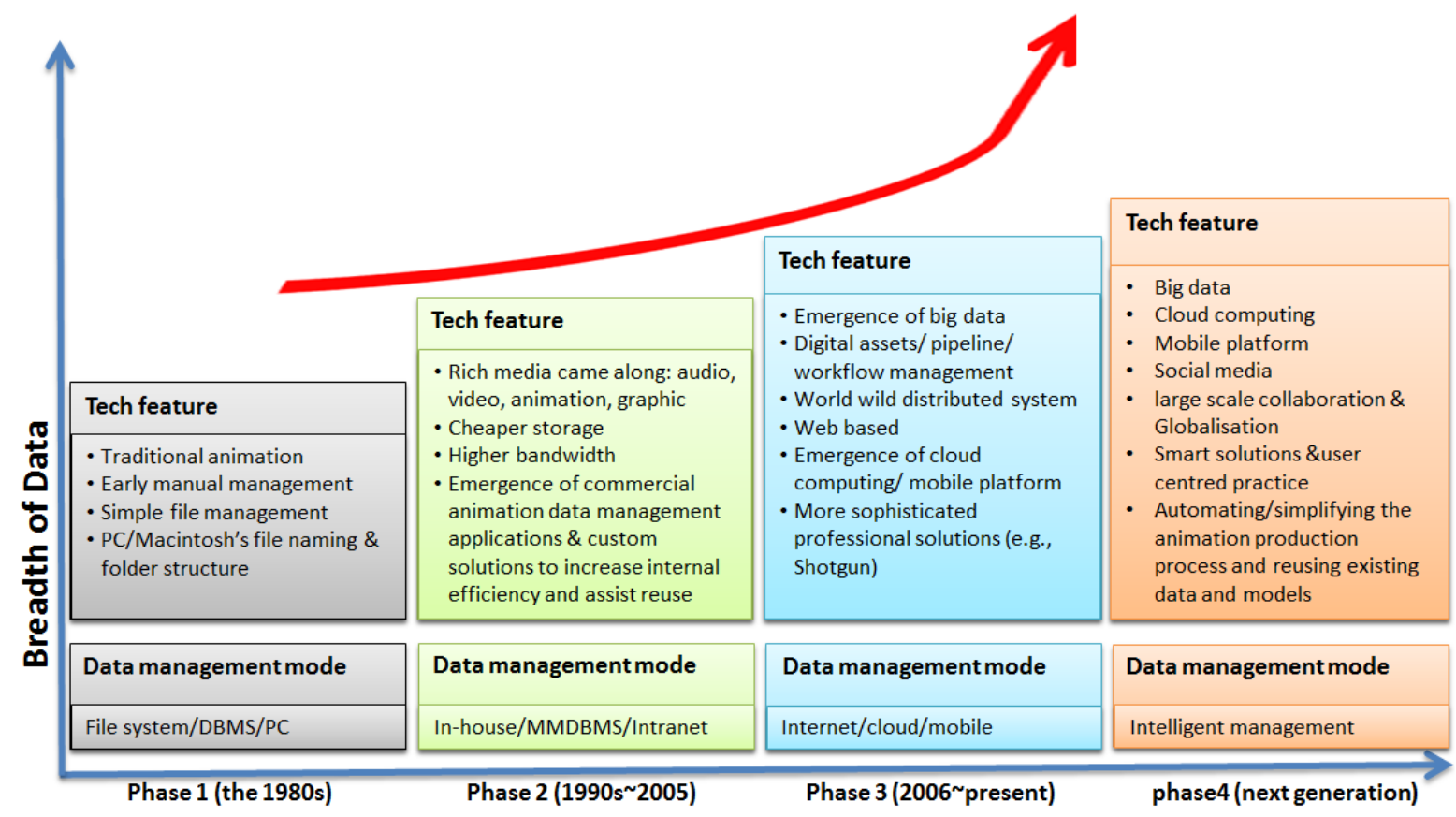

Fig. 1. Evolution of animation data management

\subsection{Phase 1 (the 1980s)}

In this phase, technological innovation in computer science greatly stimulated computer animation development and production. A most important advance is the invention of the computer hardware that significantly promoted the computing power and provided a strong foundation for computer animation production. In the early 1980s, Silicon Graphics, Inc. (http://www.sgi.com/) was founded in California by Jim Clark. Geometry Engine, a powerful semiconductor chip and the IRIS (Integrated Raster Imaging System) were initially produced to give the graphics workstations great computing power to generate sophisticated three-dimensional graphics. LINKS-1 Computer Graphics System is a supercomputer consisting of 257 microprocessors developed by Osaka University in 1982. LINKS-1 is able to render realistic 3D graphics rapidly with the help of new algorithms (Information Processing Society of Japan, 2010). Marked by the appearance of the IBM PC (1981) and the original Macintosh (1984), a rapid development and adoption of workstations for computer graphics was observed during this time, e.g., workstations by SUN, HP, and DEC. These workstations significantly advanced the computing ability and affordability of computer graphic, and also made the cost-effective production of computer-animation films and vision games a reality. 
With the speedy development in computer hardware, computer graphic became more popular to animate graphics in the movies industry. Computer graphic algorithms, such as anti-aliased ray tracing (Whitted, 1980) and particle systems (Reeves, 1983) were developed and embedded in commercial animation tools. Commercial software products also became more sophisticated, and animation production and computer graphics companies proliferated, for example, Digital Pictures, Lucasfilm and Digital Production etc. (Carlson, 2003). In 1986, Autodesk’s first animation package AutoFlix was used with its CAD software AutoCAD. And its first full 3D animation software 3DStudio was released to the public in 1990 (Baker et al., 2010). Alias Research was founded in 1983 focusing on software for SGI workstations (Design-Engine, 2011). Wavefront was founded in 1984 developing produce computer graphics software used in Hollywood motion pictures and other industries (Carlson, 2003). And Softimage was founded in 1986. Its first product was published at SIGGRAPH' 88 in which the 3D processes including modelling, animation and rendering were firstly integrated (Digitalmedianet.com).

Computer-animated film started to appear on the public theatrical screen at this phase. Disney's TRON (1982) employed extensive graphical objects and virtual environment generated by computer animation technology, which combined computer-generated imagery with special techniques in liveaction photography. The Last Starfighter (1982) opted for computer animation special effects, instead of creating props, to enhance the realistic visual senses of the movie. Many short-films produced eagerly tried 3D animation and received industry recognition. For example, Red's Dream (1987) is a computer-animated short film produced by Pixar, which received great enthusiasm at its SIGGRAPH premiere (Price, 2009). Tin Toy (1988) won the 61st Academy Award for Best Animated Short as the first computer animation. Technological Threat (1988) is an early animation short film integrating 3D computer graphics into animation production and nominated for Academy Award in the same year with Tin Toy.

In this phase, as computing software increased in sophistication and range of applicability, and also as hardware costs decreased, information technology/system was increasingly employed to create, store and handle computer-animation data. Multimedia information used in computer generated films 
normally consisted of conventional data, text, graphics, images and sound (Gallelli et al., 1986). For electronic data, management activities included creation, editing, storage, retrieval, and transmission of multimedia documents (Weinberg et al, 1988), and many of these activities were handled using PCbased systems (Thomas et al., 1985). Desktop computers (e.g., Macintosh) were commonly used as the hardware to store and organize animation files and folders.

The user at this phase typically involved the film work manager who used personal file and naming convention. An early process of managing multimedia data involved storing was generally unstructured and potentially unrelated in nature in a typical file management system. The data management systems were susceptible to vulnerable issues such as inconsistency, inaccuracy, lack of integration, and lack of security. Despite their negatives, these vulnerable issues stimulated the positive development and acceptance of innovative data management solutions. For instance, companies like Oracle, Informix, IBM and Sybase brought Relational Database Management Systems (RDBMS) into market and gained popularity (Gray, 2007), enabling the user "concentrate on what he is doing, rather than having to mess with the dirty details of opening, reading, and closing files, and managing space allocation" (Lammers, 2007).

\subsection{Phase 2 (1990 2005)}

The 1990s saw the beginning of the computer animation technology penetrating the entertainment industry, during which the technology went through enormous changes. The computer-animation hardware became more cost effective and more energy-efficient, different kinds of platform infrastructures were built, software and computer-animation algorithms continued to evolve. Consequently, computer animation rapidly stepped into human daily life, taking the form of TV programs, movies, visual games, online/console games, and so forth.

The highlight of this era lies in the emergence of new digital techniques and the ways they had revolutionised animation production. With digital technology, animation movie could be more easily created, processed, stored, and edited digitally. For instance, the hot air dispensing from the jet engine in the movie True Lies (1994) and the curling a female vampire's hair in the movie Interview with a Vampire (1994) were simulated using digital technology. 
Rapid development of computer-generated imagery (CGI) technologies contributed to the exponential growth of the animation industry in the 1990s (Pardo, 2015). CGI technologies, such as flocking, motion tracking and motion capture, were increasingly adopted in animation production. For instance, motion capture was used to animate the movement of the digital character in either 2D- or 3Danimation films. Final Fantasy: The Spirits Within (2001) appeared to be the first computer-animated film that was fully made with the motion capture technique, aiming to make it photorealistic. The Lord of the Rings: The Two Towers was the first real-time motion capture feature film, whereby the human actor's movement was captured and then applied to animate the Gollum's motion. Motion capture was also used in the production of electronic games in the mid-1995. For example, in the creation of the arcade fighting game Soul Edge in 1995, motion capture system was firstly utilized for CG effects. GIC technology became more sophisticated whereby more 'fluid' motion and characters visual effects could be created. For instance, Terminator 2: Judgment Day (1991) employed the CGI technology and created a deformable liquid metal robot, which could morph into any shapes. Jurassic Park (1993) created the 3D dinosaurs and other environmental elements (e.g., the splashing water) using CGI. Pixar's Toy Story (1995) used CGI to create realistic elaborate lighting, visual textures, and facial expressions. The box-office success of Toy Story has popularised GCI application in the production of animation movies, as evidenced by other examples such as Kung-Fu Panda (2008, 2010) and Ice Age (2002, 2006, 2009, and 2012).

The sophistication and quality of animation software continued to improve, especially in the domain of three-dimension (3D) animation, which was increasingly used in the production of film, television broadcast, gaming, corporate and industrial design, education, medical, and web design. For instance, in 1996, 3D Studio Max was set up by Autodesk and gained widespread popularity because of its economic and quality features. 3D Studio Max was rebranded to 3dsMax and then to Autodesk 3ds Max (autodesk.com). In 1998, Maya 1.0 was released as a new 3D flagship product by Alias and very shortly it became the most popular animation tool used in the computer animation industry. In 2003, because of Maya, Alias was presented with an Academy Award for Technical Achievement. Maya was rebranded to Autodesk Maya after it was acquired by Autodesk (Cohen, 2005). 
The Internet, a major digital revolution in human history, provided a more convenient way of disseminating and managing data. With the rapid development of cable, animation companies increasingly took advantage of the internet to distribute and share animation data with their partners. Simultaneously, consumers also became familiarised with the internet and learnt to access animation content online (e.g., films and games), and this emerging consumer behavior fuelled the demand for more digital content and digital platforms of computer animation.

Whilst CGI technology promoted the animation production, it presented an imminent issue to the animation industry, namely, the creation of mammoth animation data. Animation production can be labour-intensive, whereby quality moving imagery relies heavily on manual operation from a large number of animators. For example, character modelling and motion creation is typically more time consuming than the production of traditional cel animation. Moreover, a rendering task in a feature film can easily take more than one year for computation and production. In the Jurassic Park film (1993), rendering dinosaurs was reported to take two to four hours per frame. Toy Story (1995) consisted of 114,240 animation frames in the final film and required 800,000 machine hours to render at 2 to 15 hours per frame. Toy Story 2 (1999) was generated on 1,700 computer processors, consisted of 122,699 frames, each frame took around three days for rendering, and thus resulted in a total of 368,097 machine days of rendering. The frame painting team of Toy Story 2 created 10,000 images to define the characters' skin tones and generated around 17 gigabytes of data (Quinn, 2000). In Toy Story 3 (2010), a frame, on average, took seven hours to render, and some were reported take up to 39 hours of intense computing from Pixar's server farm. According to Moore's Law, the computing power doubles every 18 months. Over the 15 years in this era, a modern computer has become $1000 \mathrm{x}$ faster than before, and, yet, rendering remains time and labour consuming because of the mammoth volume of data this activity creates (Good, 2011) to meet user's demands on high quality images.

In this era, technology tools also experienced major changes, whereby hardware became cheaper and more energy-efficient, and various animation platforms or infrastructures became accessible (e.g., the Internet). According to Weinberg (Weinberg, 1995), because of the more economical and accessible technology tools, digital media production evolved to be a highly collaborative activity that involved 
teams of people working with digital resources in different locations. Animation companies began to explore new ways of organising digital data in order to improve data management efficiency and data reuse internally. Different from the desk/PC-based file management or database applications mentioned in Phase 1, cost-effective networking and data management were employed in dataintensive applications like digital postproduction (Habib et al., 2000). As under layer infrastructure, animation studio intended to design intranet in order to provide effective and efficient data management. Some main considerations surrounding the intranet includes: 1) file server/proxy placement, 2) file allocation (still images, audio and video in the case of animation), and 3) network architecture (Habib et al., 2000.). To effectively store and manage digital data of various types (e.g., text, images, graphic objects and animation sequences) various formats, Multimedia Database Management System (MMDBMS) emerged as a popular DBMS (Berra et al., 1995). Based on the distrusted network architecture, MMDBMS enables companies to effectively organize store, manage, and retrieve multimedia information from a multimedia database (Ghafoor1995.). Advanced MMDBMS solutions in this era included Oracle 10g, IMB DB2, and IBM Informix (Robertson, 2013), and some MMDBMS solutions (e.g., DISIMA) offered a function of simple content-based querying (Oria et al., 2000).

\subsection{Phase 3 (2006 present)}

In this phase, computer animation has undergone many profound changes. Chief among them is platform innovations. Digital platforms (e.g., smartphone and tablets) have titillated consumer appetite for novel animation content, and consequently, have vitalised the growth of the computer animation. Current animation trends include interactive platforms, such as moving video to mobile devices, to the Internet and to social networking sites (Cardillo et al., 2006; Raugust, 2007).

According to the report "Digital, Social and Mobile in 2015" (Kemp, 2015) from We Are Social (http://wearesocial.net), the digital world experiences major growth and almost $42 \%$ of the world's population are reported to have accessed to the internet in January 2015. Mobile's share of global web traffic leapt $39 \%$, with one-third of the web pages are accessed via smartphones. Social media also 
grows at a rapid pace, whereby 29 percent of the world populations are active internet users and 50 percent are active mobile users.

Innovative interactive digital platforms enable animation consumers to share and exchange favourite digital data with others. Some avid animation fans even opt to participate in the animation creation process with the help of up-to-date animation technology (Benkler, 2006; Flowers et al, 2008). These innovative platforms also enable animation production companies to expand their market segments and targeting. For instance, the target audience of the Simpsons and King of the Hill, as the prime-time shows on TV, is not only limited to young children, but also includes the adults of the family members (Digital Vector, 2016).

As stated earlier, the emergence of novel animation platforms has great effect not only on the end-user consumption but also on the computer animation production. One typical example is the sale of DVDs and TV programs, which was the traditional revenue source for the animation industry. Over the last decade, however, there has been a gradual drop in this traditional revenue source due to technological advances and changes in consumer preferences pertaining to animation content. That is, animation content is increasingly delivered via Internet, mobile platforms, digital TV and consumed in real time by consumers. APPs appear to be most widely adopted and can be attributed to its flexibility to be run on various mobile devices (e.g., smartphones and tablet computers). Online application stores, such as the App Store and Google Play, provide a variety of mobile applications for downloading. Mobile platforms provide a new way for constructing, downloading, and updating computer animation products in this phase.

This phase also observes the emergence of global or international exchange and partnership relating to animation production activities other than the increasing adoption of mobile platforms. According to the Global Animation Industry Report 2014 by Animation Xpress, the output value of the global animation industry in 2013 was about 222 billion USD. International cooperation and co-production between various countries has become a desired strategy (AnimationXpress Team, 2014).

Consequently, in this phase, computer animation has become even more data-intensive due to the global development and application of even more sophisticated animation production techniques. 
Effective data management has become a focal attention to animation production companies and popular issues of interest include optimal and real-time processing of animation data (e.g., creation, use/reuse, and repurposing), management of "big data" (e.g., storage, organization, retrieval, and reuse). This era has provided the fertile environment of developing professional software, such as Shotgun (https://www.shotgunsoftware.com), Alienbrain (www.alienbrain.com) and TACTIC (www.tactic.net), which facilitate animation production companies in managing and monitoring animation workflow and data.

\subsection{Phase 4 (next generation)}

The animation industry has experienced, and will continue to experience, the evolving changes of computer animation technology. These changes have resulted in major innovation relating to animation production process and the platforms employed for storing/managing animation data, as well as the ways consumers desire to access animation data. And also, these changes are constant in relation to the nature, quantity, and quantity of animation data produced and consumed. Phases 1,2, and 3 identify and explain the challenges that have been and are being faced by animation production in the past four decades. Conversely, Phase 4, which is discussed here, proposes potential challenges that will be faced by animation production in years head. Phase 4 also proposes solutions to tackle the challenges.

\section{New user and content}

The new generation of animation-content consumers, also known as the "digital natives (Thompson, 2013), are born in a rich media society and interact with digital technologies from an early age. Surrounded by digital media in daily lives, the digital natives crave for, and indeed demand, novel, interactive and immersive animation experiences. The next generation of animation products and content, therefore, must fulfil this craving, and demand, of these digital natives to win their hearts and wallets. Mobility will be an inherent feature in the next generation of animation content because the digital natives are always connected with their mobile devices (e.g. smartphones and tablets) that are constantly connected to the internet. The digital natives frequently rely on their mobile devices to communicate, learn, experience entertainment, research, and interact with other people. 


\section{New Technology}

How to provide the digital natives with more engaging and immersive experiences will be an area of interest to computer-animation researchers and practitioners. An array of new animation technologies and applications are rapidly emerging, which offers a plethora of research topics and strategies pertaining to consumer experiences, engagement and enjoyment. Innovative animation technologies and platforms may improve, or speed up, the creation of highly sophisticated and yet highly interactive animated characters.

An innovative platform essential to animation production and data management is cloud computing, which represents a buzzword frequently discussed in academic research. Partnered with mobile and wireless network technology, the cloud computing offers more mobility, flexibility and accessibility, which will bring animation production to the next level. For instance, equipped with either a smartphone/tablet or a wearable device, consumers will be able to enjoy animation content at any time, in (almost) anywhere, and with anyone they desire.

The birth of social media also creates a new platform for animation. Social media, a web-based and mobile-based internet application, can be used for creating, accessing, and exchanging computer animation content with ease in the future. Recently, some artists use Facebook to publicize their animation products and exchange ideas with peers resided in varied geographical locations. Some animation companies employ social media as an alternative channel to promotion their work or projects in conjunction with their official websites. Social media provide animation artists and companies with a perceivably controlled and safe environment where they can research, test and/or solidify new ideas with target customer segments.

The current boundary of computer-animation product will be further pushed by 3D printing, remote rending farm, the mix of western and eastern style in animation production, non-photorealistic rendering, natural interaction and immersive experience etc. According to the report by Grand View Research (grandviewresearch.com), hybrid animation combining 2D and 3D animation, the 3D animation education sector, free and open source software for video gaming, interactive 3D 
application, 3D printed models, visual effects, 4D technology, and creating animated films are also forecasted to be future trends in animation production.

\section{New community}

Animation production involves frequent and active collaboration between multiple professionals on a large scale communities such as, for example, script writers, trained artists, computer technicians, equipment specialists, distributors, and digital television providers. Collaboration and synergy will, therefore, be an emerging issue in the future production of animation content. Animation production companies will face many co-production and co-delivery opportunities because of the development of next-generation technologies and globalisation in consumer markets. For instance, the 3D animation market is expected witness rapid growth across various end-use applications over the forecast period.

As a result of emerging collaboration between animation professionals from various geographical locations, the management process of animation data will have to more "intelligent" in order to cope with the increasing mammoth amount and complex nature of data. Grid computing model is forecasted to be widely adopted in order to provide seamless and scalable access to distributed resources, whereby hybrid storage and distribution infrastructure will be developed to facilitate documentation and evaluation of animation content, and whereby mobile accessibility will be activated to facilitate information extraction and exchanges between internal and external parties working in an animation project.

In brief, the identification of the various evolution phases related to computer-animation production and data management has presented several issues, which revolve around four key domains as discussed, namely, technology, content, user, and community. These domains support the usefulness of the open-production model for analysing data management practices in the computer-animation context. The open-production model will be proposed and explained in the Discussion and conclusion section. 


\section{Emerging issues}

\section{1 "Big" animation data}

Just as the Industrial Revolution created an entirely new way of life, the big data and analytics are changing the landscape of the whole world. Accompanied by the booming of the global animation and gaming market in recent years, more challenges arise in the computer animation, especially the way we manage the animation data. There is no doubt that the animation industry is currently experiencing an extraordinary accelerating increase of hybrid animation data. The amount of the data generated during the last few years exceeds the sum of the pervious digital data (Desai, 2014).

From the aspect of animation content, one typical example is the data growth with the increasing complexity of 3D animation character. To satisfy audience's ever-increasing demand on higher quality of animation content, character modelling becomes more complex, which inevitably requires more powerful computation and advanced technologies. Sulley, a Pixar monster character, firstly appeared in Monsters movie in 2001, who had 1.1 million hairs at that time. Well, in the movie of Monsters University (2013), the number of Sulley's hairs had grown up to 5.5 million.

Facing with the rapid data growth, Pixar improved its computing power from the aspect of technology. Angelique Reisch, Pixar's technical lighting director, had showed a graphic to highlight the number of computer processors taken to create individual movies over the years (Vanian, 2015). As illustrated in Fig. 2, it took about 3000 processors to produce the movies The Incredibles (2004) and Cars (2006), and for Monsters University (2013) and Inside Out (2015), processors number has reached up to 20,000 .

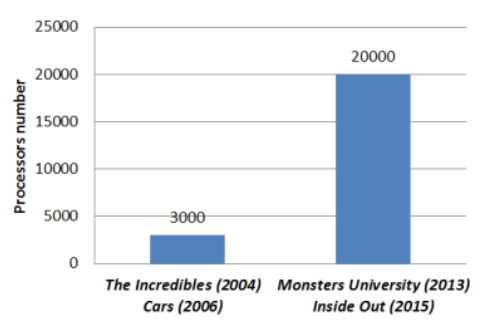

Fig. 2. Pixar processors grows in recent years 
Both the increasing complexity related to animation content and technology has presented major challenges to animation companies. Almost all the people working in this production processes have to face the issue of rapid data expanding. When several hundred video animation engineers and artists are simultaneously working on shows, each individual requires real-time access to multiple renderings of the project he or she is working on. Terabytes of animation data needs to be handled and managed in real time due to the expanding production schedule. As a result, in a daily movie production process, around 100 terabytes of big data is "in play" at any one time.

Conventional tools (e.g., the relational database management system) lacks the capability of manage surging volumes of the hyper type animation data. Movie animation and rendering firms cannot accomplish any of this work without a well-developed strategy for managing chunks of big data that come in various forms of data files including, for example, video clips, audios, 3D geometry shape, texture, motion files et cetera. The exponential growth of animation data is urgently requiring the development and employment of advanced technology and tools for handling and processing.

\section{2 "Smart” Information Systems}

Big data is on the horizon, which drives the revolutionary collaboration models of today's eInfrastructure to make it more broadly accessible and applicable. Conventional tools such as Relational Database Management System do not have the capability to manage surging volumes of unstructured data. The European Commission's Digital Agenda highlights that immediate action needs to be taken - "The Strategic Coordinating Committee for Information and Data (SCCID) recommendations highlight the need to adopt a best practice guide to data management, clearly define "open access" to data in science, explore the merits of regarding data as a publication and provide support on data management for science" (cordis.europa.eu, 2011).

\subsubsection{Current Animation Data Management System}

The management of digital data is an emerging issue, and also an opportunity, for all stages of the animation production. This animation data, often treated as some kinds of "assets", exists in wide variety of forms, such as text files, audio files, video files, texture files, graphic files, 3D model files, 
motion files, scene files, and many other types. Also, within each of these types of file, the file may even be in different formats, such as a graphic file could take the formats of the JPEG, TIFF or BMP etc. and the 3D model files could be the formats of *.ma or *.mb for MAYA, and *.max for 3DMax. As the core of the animation production, these digital assets are expensive to create or acquire. Thus, the reusability of animation data is also an important concern. Once the digital asset is created, it is necessary for that asset to be securely stored and indexed in a fashion that allows it to be easily retrieved, and to be maintained in a manner that any revisions made are authorised and recorded.

The mammoth and diverse nature of digital media data has presented extensive challenges for managing the animation data created for animation production. A number of applications have been attempted to address some of the challenges. For example, Digital Asset Management system (DAM), a typical data management system currently used in computer animation industry, natively manage files likes images, audios, videos, and the like, and offer thumbnails, streaming previews, metadata extraction, and other special features to make working with such files easy. This system is appealing to animation practitioners because it can track all assets, view thumbnails of that asset as well as being able to search for an asset based on tags. There are also several solutions for the broadcast industry and TV news specialising in the management of animation products in relation to archival/retrieval, creation, and broadcasting.

Despite the advantages, however, the ability to manage digital assets is less than satisfactory. Existing solutions, like Alienbrain is more or less a classic file store and sharing system without intelligent features to promote efficient extract and reuse of information, inhibiting flexibility and increasing complexity of the creativity practices. Shotgun is an animation production toolset for VFX, animation, and games teams, which is more of a production tracking system rather than an asset management system. It appears more suited to production workflows (task management, scheduling, high level breakdowns etc.) rather than integration with artist applications to load assets from disk.

Another outstanding issue is that those aforementioned systems lack of the support of specific content-related functionality. To promote the reusability and accessibility of vast data created in animation production, animation data and information extraction/display is highly expected. However, 
current animation data retrieval is mainly text-based, which index the metadata such as keywords, tags, or descriptions associated with the data files and rely purely on metadata are dependent on annotation quality and completeness. Having humans manually annotate digital assets by entering keywords or metadata in a large database can be labour intensive and time consuming, and may not capture the keywords desired to describe the desiring data. Multimedia information retrieval search is still a grand challenging and interesting problem (Mei et al., 2014).

Actually, the content-based retrieval is one of the most important functions that future intelligent data management should provide for the purpose of animation data achieving and reuse in a higher efficient and more user-friendly way. Content-based retrieval could provide the facility of searching the animation data by analysing the content of the animation assets rather than the metadata such as keywords, tags, or descriptions associated with the data files (Fisher et al., 2010). The content used for retrieving might involves colours, contour profile, textures, motion trail or any other information that can be derived from the animation files (Funkhouser et al., 2003; Eitz et al., 2012). The content-based retrieval is desirable because it allows the user to customize the search queries for digital assets stored within the system and also, allows the user to customize the display of the results of the search queries in order to optimize the search routines.

And also, in the recent years, semantics and ontology are begun to be used to describe the semantics of animation data and retrieval. Defining semantic concepts, inferring using rule and combining the semantic concepts and visual features, semantic modelling and ontology based retrieval could reduce the semantic gap between 3D model low-level features and high-level semantic to achieve a better retrieval performance and promote the reusability (Ohbuchi et al., 2007; Wang et al., 2008; Kassimi et al., 2012).

\subsubsection{The Cloud}

Another emerging issue faced by animation production companies is the aforementioned applications lack the capacity to provide a distributed architecture to balance the load and usage of the digital assets between different locations in an efficient and optimal manner. These applications are also 
short of the capacity that allow for local storage of the assets at high-usage locations while still maintaining central control of the data and their use.

Normally big animation studios currently have a worldwide distribution (Yoon et al., 2010). The animation data needs to be shared and processed collectively through network, for example, the render farm, where the main calculation takes place. But this may lead to the latency problem even the different sites are connected through high speed pipes (10 GB e.g.).

One possible network solution is to use NFS to cache across wide areas by making the data local, which reduces the latency and greatly affects the productivity (mandetech.com, 2011). However, with the rapid expanding of the computer animation, as a result, the complexity of animation data makes it hard to maintain, resulting in considerable costs and development risks. With increasing demand of high precision, managing growing volumes of hyper type animation data becomes a big challenge, which cannot be overcome by simply adding new servers on the network, such as the NFS.

Cloud platform is an emerging solution that focuses on providing a scalability and high performance network environment, which is consider as a ubiquitous, convenient, on-demand data computing and storage solution for the animation industry. On this platform, the main services provide the animation industry the functions of cloud computing and online data storage. Via the Internet, cloud computing and cloud storage offer users and enterprises convenient solutions to store and retrieve animation data and access computing services from cloud services.

One successful example is the usage of could platform for the production of one DreamWorks film, How to Train Your Dragon 2. The creation of this animation generated half a billion files and the animation data is enormous. It needs thousands of computing cores to keep working corporately on the rendering task for 75 million hours. For the huge animation data processing, DreamWorks' private cloud platform is used, which consists of three distributed data centres and 20,000 computing cores (Curtis, 2014).

These days institutions involved in an animation production project are often geographically separated. There may be offices needing to pool resources that are separated by great distances. The 
transfer of animation data resources between these offices frequently creates many problems in tracking the digital assets. By buying or leasing cloud service from the service providers, animation companies now can take advantage of the storage capacities of cloud computing. It is expected that, in the near future, provided with faster cloud computing and larger cloud storage capacity, the storage challenge presented by the huge animation data will be relieved because of the cloud platform.

Pursuing better animation experience, a higher resolution and more life-like motion are required in the animation products, which will inevitably result in the data expanding for rendering and storage. The animation data generated during the creation of the animation movies and visual games will continue growing rapidly in the future. There is no doubt that the big data revolution will dramatically alter the data management and processing practices of the animation industry. Current practices relating to animation data management (e.g., digital content/asset management systems) and production management toolset (e.g. asset management) have laid the foundation for the development of modern computer animation.

With the expansion of the animation production, the next evolution of animation data management is expected to focus on solving the growing trend of big data in animation production. As a result, animation companies are encouraged to be more proactive with their management strategies and practices relating to big data. Advanced technologies or tools and novel platforms, such as mobile computing, cloud services and intelligent data management, will shed light on the future trends of storing and processing animation data. As the animation industry globalises, the animation production will involve multiple specialists from various geographical locations, and, in turn, the animation data will become more mammoth and more multifaceted inevitably.

\subsection{Outsourcing to data management specialists}

Currently most of the animation companies have their own data centres, normally consisting of numerous powerful servers to process and manage the huge volumes of mixed types of animation data. Nowadays, however, the data volume is growing enormously as a result of more sophisticated visual effects. for instance, Lune et le Loup is a French short animation film in 2014 and, although its running time is only 4 minutes, the animation data volume of all the frames reaches up to about 1.5 
TB. The data demands of the feature animation films are even bigger today. Almost all the feature films runs for 90 minutes or longer and are usually shot at 24 FPS (or even higher, e.g., 48 FPS). The production of each frame involves using hundreds of digital asset files. As a result, the creation of a feature animation film could often generate as many as 500 million files (Shamoon, 2014).

To meet these big data production needs and reduce the data managerial costs, as a result, some animation companies have started to outsource their animation data management to the third-party professionals. One typical example is DreamWorks's handing over its data centre to HP. The global director of infrastructure operations at DreamWorks Animation, Michael Cutler justified that the data outsourcing enables the company to completely concentrate on animation creation and not to be distracted by maintenance activities related to IT infrastructure. He said: "Data centre management comes in and lifts up all the daily routine things that we do; the inventory, the asset management, the configuration management database...These kinds of aspects in our infrastructure are taken care of; we don't have to think about them anymore. It allows us to take time and our engineering resources to work with the people at HP to drive innovation even further." (Colyer, 2015).

\section{Discussion and conclusion}

\subsection{An Open Production Model}

Extant literature has partially discussed the development of animation industry in relation to such issues as specific technologies, animation companies, and animation products. However, issues about the complex and systematic production of computer animation data are hardly discussed. Therefore, based on the analysis of the different phases stated in Section 2 and also inspired by ZIAIE's Open Production Communities model which provides a systematic study on the Open Production Communities from a general point of view [ZIAIE, 2014], this paper presents a theoretical model that aims to better understand the complex and systematic production process of computer animation data, in relation to especially four underlying factors: technology; content; users; and community (refer to section 2 for the definitions of these dimensions). Fig. 3 illustrates the interrelationships between the four factors and their associated activities (the arrows indicate the direction of interaction). The nature and importance of the four underlying dimensions are discussed next. 


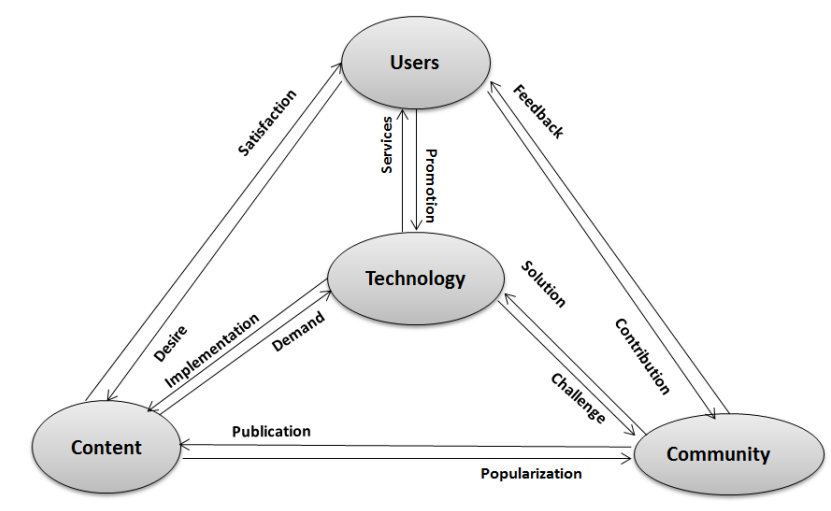

Fig. 3. An Open Production Model for computer animation

\section{Technology}

Technology refers to a core element which involves animation production processes or algorithms, hardware and software. The development of new technology plays a major role in the rapid expansion of the global computer animation and game industry, and most importantly, technology has proved extraordinarily influential in the rapid expansion of the animation data. Once new technology has been developed, deployed, accepted and used, there is usually a significant promotion of the animation production which directly generates more volume of and more complex nature of data. The history of animation embodies the development of technology (Yoon et al., 2010). It is technology, to a great extent, that drives the animation data revolution forward, just like the Industrial Revolution had promoted the world industry.

\section{Content}

The content of animation products varies in different developing periods. In the early phase, as the initial form of animation product, there were only $2 \mathrm{D}$ animation movies shown in the cinema. Then, the 3D animation films and video games entered into normal life. With the development of the computer animation, the current content of computer animation are varied in nature, such as animation movies and visual games, which are broadly used in education, business design, and animation entertainment. Animation movies (e.g., 2D animation and 3D animation) and visual games generally consist of computer games, console games and mobile games (Parkin, 2013). The further development of new animation techniques, the trend to a higher resolution (from HD to Ultra-HD) to 
offer better visual effect, and the variety of animation content has led to the surging volumes of the mixed type animation data, which increase the complexity of animation data management.

And also, the changes of the animation content dissemination drive the way of the animation data management. One typical example is the sales of animation DVDs and TV programs, which represent the traditional revenue source of the animation industry. Over the last decade years, however, more products increasingly focus on mobile platform which are more available for online watching. This mobile trend has led to a radical change of the animation content where more and more animation data transferred through the Internet and mobile platforms. As the result, animation production involves multi-platform or cross-platform data management such as Cloud storage and mobile computing.

\section{User}

Our model proposes two main types of actors constituting the user dimension: the producer, and the consumer. The producer refers to the person involve in the production of animation content, such as authors, animators, IT, broadcasters etc. The authors start the process of the innovation and then the developers enhance this creation progress as the movie development. Animators and IT specialists play central roles in the creation and dissemination activities. Broadcasters limit market access and capture a large share of the income. The producer represents the main contributor of the generation of huge amount animation data during the process of producing and disseminating animation contents. The consumer refers to the person or the organization that uses or consumes animation services, who also significantly influences the development of animation data. Consumption patterns and habits can mould the motivations of animation production. Consumer interests or preferences influence the animation content created by animation companies and in turn animation data management practices.

\section{Community}

Animation community refers to a group of academic and commercial researchers who work in the domain of computer animation. They congregate, and exchange and discuss issues or ideas with each other. With the help of the modern communication technology, the community can adapt to almost any 
research need, exhibit creative stimulus material, and gather ideas for innovation and co-creation. They are the main contributors of the revolution of new animation technologies and accelerate the development of animation data management in a direct or indirect way. Using this model, we could conduct a better understanding on how computer animation has evolved during the decades at different phases. The detail is as shown in Table 2. This proposed theoretical model is expected to present the cornerstone of computer animation industry and facilitate to have an overall understanding of the feature of the animation industry.

Table 2 - Animation evolution factors analysis using the Open Production Model.

\begin{tabular}{|c|c|c|c|c|}
\hline & Technology & Content & User & Community \\
\hline Phase1 & $\begin{array}{l}\text { Fast development in } \\
\text { computer hardware/ } \\
\text { workstations / IBM PC, } \\
\text { Macintosh } \\
\text { Computer graphic / } \\
\text { software in animation } \\
\text { production } \\
\text { File management system / } \\
\text { PC-based systems/DBMS }\end{array}$ & $\begin{array}{l}\text { Population of Computer } \\
\text { generated animation films } \\
\text { Special effects were } \\
\text { involved } \\
\text { 3D animation appeared } \\
\text { Products: TRON (1982), } \\
\text { Red's Dream (1987), Tin } \\
\text { Toy (1988), Technological } \\
\text { Threat (1988) }\end{array}$ & $\begin{array}{l}\text { Producer: manual/PC } \\
\text { assisted } \\
\text { Consumer: mainly young } \\
\text { children in theatres/ on TV }\end{array}$ & $\begin{array}{l}\text { Computer graphics } \\
\text { companies: Digital } \\
\text { Pictures, Lucasfilm, Digital } \\
\text { Production } \\
\text { Animation software: } \\
\text { AutoCAD, 3DStudio, } \\
\text { Softimage } \\
\text { Data management } \\
\text { companies: Oracle, } \\
\text { Informix, IBM and Sybase }\end{array}$ \\
\hline Phase2 & $\begin{array}{l}\text { Hardware became cheaper } \\
\text { and energy-efficient } \\
\text { Digitalisation } \\
\text { CGI significantly promoted } \\
\text { animation } \\
\text { Internet provided a more } \\
\text { convenient way of }\end{array}$ & $\begin{array}{l}\text { Visual effects, character } \\
\text { modelling, motion } \\
\text { creation } \\
\text { Online animation content } \\
\text { Visual game } \\
\text { Products: Terminator 2: } \\
\text { Judgment Day (1991), }\end{array}$ & $\begin{array}{l}\text { Producer: still labour- } \\
\text { intensive } \\
\text { Consumer: visual game } \\
\text { player/TV viewer/Movie } \\
\text { audiences; access animation } \\
\text { content online }\end{array}$ & $\begin{array}{l}\text { Internet } \\
\text { Enormous } \\
\text { development in 3D } \\
\text { animation software: 3D } \\
\text { Studio Max, 3dsMax, } \\
\text { Maya 1.0, Autodesk } \\
\text { Maya } \\
\text { Developments, mergers }\end{array}$ \\
\hline
\end{tabular}




\begin{tabular}{|c|c|c|c|c|}
\hline & $\begin{array}{l}\text { disseminating and managin } \\
\text { data } \\
\text { Professional animation } \\
\text { software was widely used } \\
\text { Networking based } \\
\text { multimedia database }\end{array}$ & $\begin{array}{l}\text { Soul Edge (1995), Toy Story } \\
\text { (1995), Toy Story } 2 \text { (1999), } \\
\text { Final Fantasy: The Spirits } \\
\text { Within (2001), The Lord of } \\
\text { the Rings: The Two Towers } \\
\text { (2002), Ice Age (2002 }\end{array}$ & & $\begin{array}{l}\text { and deals in the } \\
\text { companies: Autodesk, } \\
\text { Alias } \\
\text { Advanced MMDBMS } \\
\text { solutions: Oracle } 10 g, \\
\text { IMB DB2, IBM } \\
\text { Informix, DISIMA }\end{array}$ \\
\hline Phase3 & $\begin{array}{l}\text { CGI becomes } \\
\text { more matured } \\
\text { Mobile platform/APPs } \\
\text { Social network/social } \\
\text { media } \\
\text { Data-intensive/ global } \\
\text { development }\end{array}$ & $\begin{array}{l}\text { Significant decline of } \\
\text { traditional products } \\
\text { Mobile-based animation } \\
\text { Everything is online } \\
\text { Apps }\end{array}$ & $\begin{array}{l}\text { Producer: adapt production } \\
\text { and products to consumer, } \\
\text { expand global animation } \\
\text { market by novel channels } \\
\text { Consumer: consumption } \\
\text { pattern \& habit changed; } \\
\text { more adults, even the whole } \\
\text { family, become animation } \\
\text { consumers and lovers. }\end{array}$ & $\begin{array}{l}\text { Mobile platform } \\
\text { community } \\
\text { Social network } \\
\text { Globalisation, } \\
\text { international exchange } \\
\text { and cooperation } \\
\text { Effective data } \\
\text { management/ } \\
\text { professional software: } \\
\text { Shotgun, Alienbrain, } \\
\text { TACTIC }\end{array}$ \\
\hline Phase4 & $\begin{array}{l}\text { Mobile based } \\
\text { Social media } \\
\text { Big data } \\
\text { Intelligent data } \\
\text { management }\end{array}$ & $\begin{array}{l}\text { Expected to offer a more } \\
\text { engaging, interactive and } \\
\text { immersive animation } \\
\text { experience: } 3 D \text { printing, } \\
\text { remote rending farm, the mix } \\
\text { of western and eastern style in } \\
\text { animation production, non- } \\
\text { photorealistic rendering, } \\
\text { natural interaction and } \\
\text { immersive experience }\end{array}$ & $\begin{array}{l}\text { Producer: co-production } \\
\text { and co-delivery; incorporate } \\
\text { next-generation } \\
\text { technologies and } \\
\text { globalization; mobile } \\
\text { accessibility to facilitate } \\
\text { information extraction and } \\
\text { exchanges; professional data } \\
\text { management } \\
\text { Consumer: "New media }\end{array}$ & $\begin{array}{l}\text { Cooperative research } \\
\text { between multiple } \\
\text { professionals on a large } \\
\text { scale communities } \\
\text { Global animation } \\
\text { industry } \\
\text { New trend in research } \\
\text { focusing on next } \\
\text { generation technologies }\end{array}$ \\
\hline
\end{tabular}




\begin{tabular}{l|l|l|l}
\hline & & generation" needs more & Hybrid storage and \\
& interactive and immersive & distribution \\
animation experiences, & infrastructure \\
& inherent feature of mobility & \\
& & & \\
\hline
\end{tabular}

\subsection{Greater collaboration between practitioner and research communities}

Extant literature indicates a lack of collaboration between animation practitioners and academic researchers working in the computer animation context. There needs to be a greater or more frequent collaboration between the various communities, particularly between the practitioner group and the research community. The research on the next generation of novel or intelligent solution for animation production, especially related to the capability of handling huge amount of animation data and analysing information, has gained momentum in Europe (e.g., MEDIA Programme (2007-2013) of European Commission [European Commission, 2014] and the MEDIA sub-programme of The Creative Europe programme [European Commission, 2015] etc.).

The research hitherto focuses on the reusability and accessibility of vast data created in animation production to facilitate human creativity, and topics of interest include information extraction, document summarization, semantic web, visual analytics, and development of next generation techniques related to computer animation. Intelligent data management frameworks or practices, that address the capability of handling mammoth amount of data and of analysing or reusing animation data to facilitate human creativity, will be the "hot issues" to animation practitioners and academic researchers.

More collaboration between the animation practitioner and the research communities will, therefore, help to advance the existing knowledge of animation computer data. Collaborative research topics can includes knowledge transfer between practitioners and academics, researchers and technology, tools and software prototypes, as well as, a roadmap for a restructuring of the research area and 
development/guidance of future standards and policies. These topics fit well with the European research innovation and challenges. Investment in these research topics will contribute to the advancement of data management fields in EU such as computer science, engineering and digital technology. These research topics will also contribute to the ever evolving field of animation and digital economy, bringing new vision and new thinking to computer animation such as, for example, combining the emerging challenges of intelligent big data management with creative and technical innovation.

\subsection{Conclusion}

The computer animation field takes a distinctive path which marries creative art and design with mathematical and computer science. Not only has computer animation served the creation of Hollywood blockbuster films and interaction in games, but more importantly and usefully, it has served other sectors such as manufacturing and design, health care, education, and science. It has been a golden era in the past thirty years for the ever evolving field of computer animation, with novel hardware and gadgets, and numerous techniques have been developed. We are approaching another evolution phase where animation consumers will demand more immersive and engaging experiences and where "smarter" information system will occur to shape, or dictate, animation design and production activities, and, consequently, animation companies will need more sophisticated systems and hybrid models to store and handle the escalating amount of data that come from various sources. This paper has taken the pioneering step to summarise and explain the evolution phases related to computer-animation data management and then proposed several issues that are insightful for animation practitioners and academic researchers. Moreover, this paper supports the utility of the open-production model for examining data management issues, which will provide food for thought for academic research and advance extant literature related to computer animation data.

\section{References}

AnimationXpress Team. (2014). Global Animation Industry Report 2014: Strategies, Trends \& Opportunities for the \$US 222 Billion Industry. Retrieved from: http://www.animationxpress.com/index.php/animation/global-animation-industry-report-2014strategies-trends-opportunities-for-us-222-billion-industry 
Autodesk.com. History of Autodesk 3ds Max. Retrieved from:

http://area.autodesk.com/maxturns20/history

Baker, D., Blevins, N., Hadis, P., \& Kirvan, S. (2010). The History of 3D Studio-Tom Hudson interview.

Benkler, Y. (2006). The Wealth of Networks: How Social Production Transforms and Markets and Freedom. Yale University Press.

Berra, B., Nwosu, K., \& Thuraisingham, B. (1995). ACM Multimedia'94 conference workshop on multimedia database management systems. ACM SIGMOD Record, 24(1), 70-72.

Cardillo, B., Jeffrey, L., \& Allen, J. (2006). Converge or die - Surviving the digital media maze. In T. Jeffrey (Ed.), Film Business: A Handbook for Producers (pp. 49-57). Crows Nest, N.S.W. : Allen \& Unwin.

Carlson, W. (2003). A critical history of computer graphics and animation. The Ohio State University.

Cohen, P. (2005). Autodesk acquires Alias. Retrieved from:

http://www.macworld.com/article/1047264/alias.html

Collins, J. (1997). SIGGRAPH: Past and Present. Animation World Magazine, 2(5).

cordis.europa.eu. (2011). Rising to the Big Data Challenge. GRDI2020 Workshop on Global Research Data Infrastructures 2020. Retrieved from: http://cordis.europa.eu/event/rcn/128230_en.html

Curtis, S. (2014). How technology is driving the next wave of film animation. Retrieved from: http://www.telegraph.co.uk/technology/news/10849028/How-technology-is-driving-the-next-waveof-film-animation.html.

Deloitte. (2010). Animation, Broadcasting, Gaming: On the cusp of growth. New Delhi: ASSOCHAM.

Desai, B. C. (2014). The state of data. Proceedings of the 18th International Database Engineering \& Applications Symposium, IDEAS'14. ACM New York, NY, USA ,77-86.

Design-Engine. (2011). A History Lesson on Alias 3D Software. Retrieved from: http://designengine.com/a-history-lesson-on-alias-3d-software/

Digital Vector. (2016). Global Animation Industry: Strategies, Trends and Opportunities Report.

Retrieved from: http://www.digital-vector.com/Global\%20Animation\%20Industry\%20-

$\% 20$ Sample\%20Page.pdf

Digitalmedianet.com. Corporate profile on Softimage. Retrieved from:

http://www.digitalmedianet.com/HTM/RESEARCH/Meloni/corporate/3D/Softimage.htm

Eitz, M., Richter, R., Boubekeur, T., Hildebrand, K., \& Alexa, M. (2012). Sketch-based shape retrieval. ACM Trans. Graph., 31(4), 31-1.

European Commission. (2014). Retrieved from: http://eacea.ec.europa.eu/media/index_en.php

European Commission. (2015). Retrieved from: https://ec.europa.eu/digital-agenda/en/media-subprogramme-creative-europe

Fisher, M., \& Hanrahan, P. (2010). Context-based search for 3D models. In ACM Transactions on Graphics (TOG), 29(6), 182. ACM.

Flowers, S., Mateos-Garcia, J., Sapsed, J., Nightingale, P., Grantham, A., \& Voss, G. (2008). The New Inventors: How users are changing the rules of innovation.

Funkhouser, T., Min, P., Kazhdan, M., Chen, J., Halderman, A., Dobkin, D., \& Jacobs, D. (2003). A search engine for 3D models. ACM Transactions on Graphics (TOG), 22(1), 83-105. 
Gallelli, S., Iacobelli, C., \& Marchisio, P. (1986). An approach to multimedia information management. Proceedings of the 9th annual international ACM SIGIR conference on Research and development in information retrieval. ACM. 31-38.

Ghafoor, A. (1995). Multimedia database management systems. ACM Computing Surveys (CSUR), 27(4), 593-598.

Good, C. (2011). How much faster would it be to render Toy Story in 2011 compared to how long it took in 1995? Retrieved from: https://www.quora.com/How-much-faster-would-it-be-to-render-ToyStory-in-2011-compared-to-how-long-it-took-in-1995

Grandviewresearch.com. 3D Animation Market Analysis, Market Size, Application Analysis, Regional Outlook, Competitive Strategies And Forecasts, 2014 To 2020. Retrieved from: http://www.grandviewresearch.com/industry-analysis/3d-animation-market

Gray, J. (2007). Data Management: Past, Present, and Future. arXiv preprint cs/0701156.

Habib, S. J., \& Parker, A. C. (2000). Computer-aided system integration for data-intensive multimedia applications (poster session). Proceedings of the eighth ACM international conference on Multimedia (pp. 379-381). ACM.

Information Processing Society of Japan. (2010). [Osaka University] LINKS-1 Computer Graphics System.Retrieved from: http://museum.ipsj.or.jp/en/computer/other/0013.html

Kassimi, M. A., \& Elbeqqali, O. (2012). Semantic based 3D model retrieval. In Multimedia Computing and Systems (ICMCS), 2012 International Conference on,195-199. IEEE.

Kemp, S. (2015). Digital, social \& mobile worldwide in 2015. We are social.

Lammers, S. (2007). The History of FoxPro - Interview with Wayne Ratliff. Retrieved from: http://www.foxprohistory.org/interview_wayne_ratliff.htm.

Lasseter, J. (1987). Principles of traditional animation applied to 3D computer animation. In ACM Siggraph Computer Graphics, 21(4), 35-44. ACM.

Magnenat Thalmann, N., \& Thalmann, D. (1996). Computer animation. ACM Computing Surveys (CSUR), 28(1), 161-163.

mandetech.com. (2011). Data Management In Animation. Retrieved from:

http://mandetech.com/2011/04/09/data-management-in-animation/

Manyika, J., Chui, M., Brown, B., Bughin, J., Dobbs, R., Roxburgh, C., \& Byers, A. H. (2011). Big data: The next frontier for innovation, competition, and productivity. McKinsey Global Institute Report.

Markets and Markets. (2011). Animation \& Gaming Market Size and Global Forecast (2011-2016). Retrieved from: http://www.marketsandmarkets.com/Market-Reports/animation-gaming-market514.html.

Mei, T., Rui, Y., Li, S., \& Tian, Q. (2014). Multimedia search reranking: A literature survey. ACM Computing Surveys (CSUR), 46(3), 38.

Meyrowitz, N. (1986). Intermedia: The architecture and construction of an object-oriented hypemedia system and applications framework. 21 (11), 186-201. ACM.

Colyer, M. R. (2015). DreamWorks Animation hands over data centre and private cloud management to HP. Retrieved from: http://www.v3.co.uk/v3-uk/news/2411508/dreamworks-animation-handsover-data-centre-and-private-cloud-management-to-hp

Ohbuchi, R., Yamamoto, A., \& Kobayashi, J. (2007). Learning semantic categories for 3D model retrieval. Proceedings of the international workshop on Workshop on multimedia information retrieval, 31-40. ACM.

Oria, V., Özsu, M. T., Iglinski, P. J., Lin, S., \& Yao, B. (2000). DISIMA: a distributed and interoperable image database system. In ACM SIGMOD Record, 29(2), 600. ACM. 
Pardo, A. (2015). 3 Cinema and technology: From painting to photography and cinema, up to digital motion pictures in theatres and on the net. In L. Cantoni \& J. A. Danowski (Eds.), Communication and Technology (pp.57). Walter de Gruyter GmbH.

Parent, R. (2012). Computer animation: algorithms and techniques (pp. 187-198). Newnes.

Parkin, L. (2013). Global Animation and Gaming Expected to Skyrocket by 2016. Retrieved from: http://www.voiceovertimes.com/2013/12/18/global-animation-and-gaming-expected-to-skyrocket-by$2016 /$.

Price, D. A. (2009). The Pixar touch: The making of a company. Vintage Books USA.

Quinn, T. (2000). FILM REVIEW: LIGHTYEARS AHEAD -Toy Story 2; Buzz is back as THOMAS QUINN lifts the lid on Toy Story 2. The Mirror (London, England).

Raugust, K. (2007). Digital directions: indies follow majors' lead. Animation World Network. Retrieved from: http://mag.awn.com/?article_no=3331.

Reeves, W. T. (1983). Particle systems-a technique for modeling a class of fuzzy objects. ACM Transactions on Graphics (TOG), 2(2), 91-108.

Robertson, L. (2013). Methods and innovations for multimedia database content management/Current trends and future practices for digital literacy and competence. The Australian Library Journal, 62(2), $170-171$.

Shacklett, M. (2014). Movie animation firm's big data challenges present lessons to learn. Retrieved from http://www.techrepublic.com/article/movie-animation-firms-big-data-challenges-presentlessons-to-learn/

Shamoon, E. (2014). DreamWorks' New Apollo Platform - Studio Visit. Retrieved from: http://www.3dtotal.com/index_interviews_detailed.php?id=389\#.VmWj1CusUUY

Soomro, Z. A., Shah, M. H., \& Ahmed, J. (2016). Information security management needs more holistic approach: A literature review. International Journal of Information Management, 36(2): 215225 .

Thomas, R. H., Forsdick, H. C., Crowley, T. R., Schaaf, R. W., Tomlinson, R. S., Travers, V. M., \& Robertson, G. G. (1985). Diamond: A Multimedia Message System Built on Architecture. Computer, 18(12), 65-78.

Thompson, P. (2013). The digital natives as learners: Technology use patterns and approaches to learning. Computers \& Education, 65, 12-33.

Vanian, J. (2015 ). How Pixar brings its animated movies to life. Retrieved from: http://fortune.com/2015/09/14/pixar-brings-movies-life

Walker, J. H. (1988). Supporting document development with Concordia. Computer, (1), 48-59.

Wang, X., Lv, T., Wang, S., \& Wang, Z. (2008). An ontology and SWRL based 3D model retrieval system. In Information Retrieval Technology (pp. 335-344). Springer Berlin Heidelberg.

Weinberg, R. (1995). Producing content producers [computer animation]. Communications Magazine, IEEE, 33(8), 70-73.

Weinberg, R. S., \& Bozonie, M. J. (1988). A basic set of abstract object classes for representation of complex documents. ACM SIGOIS Bulletin, 9(4), 5-10.

Whitted, T. (1980). An improved illumination model for shaded display. Communications of the ACM, 23(6):343-349.

Yoon, H., \& Malecki, E. J. (2010). Cartoon planet: worlds of production and global production networks in the animation industry. Industrial and Corporate Change, 19(1), 239-271.

Ziaie P. A. (2014). Model for Context in the Design of Open Production Communities. ACM Computing Surveys (CSUR), 47(2): 29. 